\title{
My Journey with Indian Pediatrics
}

\author{
Panna Choudhury \\ Editor-in-Chief, Indian Pediatrics (2002-2007) \\ Correspondence to: pannachoudhury@gmail.com
}

My association with the journal dates back since 1982 as Assistant Editor, Executive Editor and Editor-in-Chief. I vividly remember, my previous illustrious Editor-inChief Dr HPS Sachdev handing over the job of chief editorship to me on $31^{\text {st }}$ December 2001. Though I had been associated with the journal for a long time, the enormity of the responsibility suddenly struck me. While we work within the larger medical context, the core of the journal is to make quality information and research readily available. This focus on high quality articles and easy accessibility is the foundation for our innovations and our achievements.

One of our biggest challenges was to attract quality articles. Most Indian researchers preferred to send their best work to western journals, which had good impact factors. Though Indian Pediatrics was indexed in PubMed for a long time, it was not, when I took over, included in reputed indexing services. Journals without an impact factor are not considered their worth and a listing in the JCR (Journal Citation Reports ${ }^{\circledR}$ ) is considered a status symbol for journals from developing countries. We took this up as a challenge and to our delight the journal got indexed in science citation index and current contents in its very first attempt! In February 2006 Indian Pediatrics reported "We are happy to inform our readers that Indian Pediatrics has been selected for coverage in Current Contents/Clinical Medicine and the Science Citation Index Expanded (SCIE), starting from the January issue of Vol. 42 (2005)" [1].

Maintaining quality in a scientific journal requires constant and stringent quality control. One of these is a strict peer review process. As a scientific journal that belongs to a society, we would get many articles from Academy members. In fact, the Academy even had a rule that award-winning papers would have to be submitted to the journal for publication as the first choice. However, most of these papers did not clear the peer review process. Moreover, getting quality reviewers was not an easy task and sometimes some reviewers got burdened with too many articles, which delayed the review process. The Editorial board took up the challenge and educated the society members on the importance of peer review process and the norms of a high quality scientific journal. Continued focus and optimizing of this process has been significantly important towards the journal achieving its high standards and building its reputation as a source of quality articles and research.

One of the more controversial initiatives was the limit on number of authors permissible in certain sections. This was introduced from 2003 and followed earnestly. The policy resulted in much criticism, long drawn correspondence between the Editor-in-chief and authors, and a lot of heartburn. We conducted a short study to evaluate the outcome of this policy on authorship credits. Interestingly, the policy resulted in fewer authorship credits for senior authors, presumably due to a decline in gift authorship. The journal thus decided to continue with this policy $[2,3]$.

For a journal like Indian Pediatrics, it is an extremely difficult task to meet the requirements of readers from diverse backgrounds ranging from tertiary research centers to practitioners in remote areas. It has been a constant endeavor of the Editorial Board to make the journal more accessible and readable to mainstream readers while at the same time maintaining the high standard of scientific content and adhering to a stringent peer review process. With the participation and feedback from the readers, the editorial board constantly focused on making Indian Pediatrics a reference model of how a scientific professional societal journal in this part of the world should be.

Though the focus of the journal is on publishing original research articles since inception, over the years it introduced many innovative sections to be more interactive with its readers. Another area of focus was on public health issues. In my years as Editor-in-Chief, Indian Pediatrics has been a key partner in the propagation of the messages of under-5 child survival program to practitioners, physicians and pediatricians, in line with the vision of IAP. In these issues, the journal published many consensus statements/guidelines/ recommendations of the task forces/chapters of the Indian Academy of Pediatrics, pertaining to management of diseases directly concerning under- 5 child survivals relevant to achievement of Millennium development goal [4]. Indian Pediatrics has also collaborated with Urban Health Resource Center (UHRC) to bring out a series of well-researched papers highlighting important issues on urban child health. 
In 2007, the journal was revitalized with new aesthetics, with the focus on bringing in fresh energy and making it more reader friendly. The new cover artwork was chosen from a design contest conducted amongst the members. The journal format was changed in accordance with the international standards but at the same time keeping it at decent page numbers. The Board also formulated "author information' in an elaborate way giving new directions [2].

I have been fortunate in my tenure as Editor-in-Chief to witness amazing advancement in information technology. Harnessing the power of this revolution has greatly helped the journal in becoming more accessible to its readers. In my early years, we had an incredible opportunity with the internet revolution taking place worldwide. The journal also kept pace with the rise of global technology platforms and increasing content digitization. Indian Pediatrics was one of the first few journals in the world to become full text free online. Our website had extraordinary page hits, running at almost three quarter of a million per month. In fact, Alexa Internet Inc., a California-based subsidiary company of Amazon.com dealing with web-traffic reporting, frequently rated the journal number one in its class. Maintaining a dynamic website was not an easy task those early days with need to hire server space and have dependable consultants. The team solved this to both administrative and financial gain, by training one of its staffs in technology and web maintenance.

One of the indicators of the Journal's success has been the constant request from readers about articles from past issues. While such requests were very encouraging, they were also administratively impossible to fulfill. Here too we found a solution in technology. Indian Pediatrics entered into an agreement with National Informatics Center (NIC), Govt. of India to put the journal in the Indian Medlars Center, which provided another portal for online access to full-text of Indian biomedical periodicals. An arrangement with NIC was also negotiated, to get past issues of the journal digitized. The progress was slow but with in-house efforts it was finally possible to digitize past issues up to 1991. These were uploaded on the website of the journal and received much appreciation from many developing countries.

Managing the journal has been an incredible experience, but it does come with its fair share of administrative challenges. The journal is issued monthly with a fixed date posting every month. In the beginning, that itself was an arduous task with the need to maintain several deadlines like folio preparations, press deadlines and manually handling packaging of 16000 copies and so on. Moreover, we had major limitations in the areas of infrastructure, manpower resource and finances. Our initial 'journal office' was just 2 rooms (each 12 by 6 feet), on different floors and without a proper approach road. The building was dilapidated and the rooms were windowless, which made working conditions very difficult, especially in the hot summers. Most members would do their work from their place of work and the files would be transported manually. The lack of adequate space meant, only the Editor-in-Chief would go to the office in the evening and clear large number of files that would pile up every day. The journal staff consisted of only 3 clerical level people and 2 office assistants. Finances were a major worry, as the journal was sent free of cost to all the members and the Academy already had a budget deficit. Additional income through advertisements was not an easy task, especially with academy's decision not to accept any support from industries dealing infant milk substitutes and ethical issues concerning product to be advertised.

Some relief came in an unexpected way. The journal was in litigation for a flat it had booked under Delhi Development Authority but had decided to sell to a third party as it was unable to pay its installments. In a windfall at this time, years of litigation process were sorted out, and the journal got some financial compensation as a part of the settlement. This was then utilized to procure a modest office premise in an urban village but located in central area of Delhi, just behind All India Institute of Medical Sciences. The journal also maintained financial discipline by keeping its operative cost low with direct sourcing of paper and a meager staff that worked overtime. Several other measures to improve finances included vigorous efforts to procure appropriate advertisements, selling reprint of articles, bringing out books with tie ups with publishers and many other innovative measures. The Editorial team worked very hard with a very clear job distribution between the members. The members met every 2 months and brainstormed on the problems of the journal and possible solutions. We faced some very difficult times, but they gave a chance for our extremely dedicated people to shine, and produce our most treasured achievements.

\section{REFERENCES}

1. Gupta P, Choudhury P. Impact factor and Indian Pediatrics. Indian Pediatr. 2006; 43:107-110.

2. Gupta P, Choudhury P. Indian Pediatrics: Enjoy the old wine in a new bottle. Indian Pediatr. 2007; 44: 7.

3. Gupta P, Sharma B, Choudhury P. Limiting authorship in Indian Pediatrics: an initiative to curb gift authorship. Indian Pediatr. 2007;44:37-9.

4. Choudhury P. Indian Pediatrics and child survival. Indian Pediatr.2007;44: 567-8. 